\title{
MANAJEMEN ANTARA UMAT BERAGAMA STUDI KASUS: UMAT BERAGAMA BUDHA DI TANJUNG BATU KECAMATAN KUNDUR KABUPATEN KARIMUN
}

\author{
Pipi Yulita, Ariesta, Yuhelna \\ Program Studi Pendidikan Sosiologi STKIP PGRI Sumatera Barat \\ Pipiyulita2404@gmail.com
}

\begin{abstract}
This study discusses the existence of the management of harmony between Islam and Buddhism in Tanjung Batu Kota. This study aims to describe the factors that cause religious harmony in Tanjung Batu Kota, Kundur District, Karimun Regency.This study used the conflict theory according to Lewis Coser. This research used a qualitative approach with a descriptive type. purposive sampling technique was used to select the informant that consists of 10 people. The types of data used in this study were primary data and secondary data. Observation, in-depth interviews, and document studies were used in collecting the data. Meanwhile, the data analysis unit used by the group was Milles and Huberman's data analysis, namely data collection, data reduction, data presentation, and conclusion drawing. The results of this study reveal that several factors are causing religious harmony: 1) Tolerance in the Economic Sector. 2) Inter-Religious Harmony. 3) Mutual Respect and Respect for Other Religions. 4) The Management of Religious Harmony in Tanjung Batu City, Kundur District.
\end{abstract}

Keywords: Interaction, Society, Harmony, Management.

\section{PENDAHULUAN}

Indonesia merupakan negara yang mempunyai keberagaman mulai dari agama, ras, suku, golongan, serta budaya. Tidak mudah dalam menjaga perbedaan antar umat beragama agar tidak menimbulkan perpecahan. Agama menjadi salah satu hal yang sensitif dalam kehidupan masyarakat, kerukunan antara umat beragama menjadi salah satu bagian dari kerukunan nasional yang harus mampu kita jaga rawat demi persatuan dan kedaulatan (Wiranta \& Marzuki, 2018).

Beranekaragaman krakteristik disetiap daerah menimbulkan adanya perbedaan antara satu dengan yang lain, baik etika, ras, adat istiadat maupun budaya, oleh sebab itu setiap individu dituntun mampu beradaptasi dengan baik sehingga muncul kedamaian serta ketenteraman sehingga tidak mengalami kesalah pahaman (Lubis, 2017).

Semua agama memiliki misi kedamaian dan serta merta dalam 
kehidupan tidak hanya dengan manusia, tetapi juga sesame makhluk lainnya. Menurut "trimologi" alquraan sasaran itu ditutur Rahmatan Lil Al-alamin( Anugrah dan Kedamaian untuk Alam) dalam derajat hitorynya, di samping itu memiliki tujuan sebagai sarana menyatakan secara sosial, agama juga memiliki indikasi untuk terjadinya pertikaian(Khamad, 2006).

Keyakinan itu akan membentuk perilaku baik atau buruk agama juga disebut di agama islam amal perbuatan. Dalam mempelajari agama serta memahami dimana terdapat rangkaian proses yang dapat dikatakan sebagai keyakinan, karna demikian umat beragama memiliki, kadar interpersitas yang berbeda untuk beragama serta memahami ajaran agamanyaatas kemampuan masing - masing. (Khamad, 2006).

Dengan kondisi yang beragam dengan dimana adanya macam macam suku bangsa serta agama dapat mencerminkan perbedaan itu sendiri. Dalam agama rawan sekali adanya perselisihan teruntuk itu pemerintah umat agama dalam menganjurkan untuk damai pada sesamanya. Di Indonesia tidak bisa terlepas dari munculnya puralisme agama dan keragaman manusia yang tidak dapat lagi serta merupakan bagian dari sejarah.

Berdasarkan hasil observasi yang peneliti dapatkan di mana peneliti dapatkan Fenomena di masyarakat yang berbeda agama saling berinteraksi dengan baik seperti mereka melakuakn kegitan gotong royong bersama dan merayakan hari besar yaknik hari raya Idul Fitri dan Imlek, tidak sedikit umat muslim yang ikut berkontribuksi dalam pelaksanaan acara besar tersebut. Bukanlah sesuatu hal yang mustahil terjadi. Hal ini dapat dilihat di Tanjung Batu Kecamatan Kundur Kabupaten Karimun yang dimana Tanjung Batu Kundur merupakan daerah yang masyarakatnya hetorogen. 
Tabel 1.1 Total Penduduk Berdasarkan Keyakinan Beragama di Desa / Kelurahan di Kecamatan Kundur 2017

\begin{tabular}{lcccccc}
\hline \multirow{2}{*}{ Desa/Kelurahan } & \multicolumn{7}{c}{ Agama } \\
& Isalam & Katolik & Protestan & Hindu & Budha & Konghucu \\
\hline Tg. Batu Barat & 5.610 & 62 & 514 & 1 & 394 & 27 \\
Tg. Batu Kota & 11.021 & 117 & 320 & 1 & 2.487 & 173 \\
Gading Sari & 2.197 & 6 & 25 & 0 & 15 & 10 \\
Sei Sebesi & 3.371 & 0 & 17 & 0 & 33 & 5 \\
Sei Ungar & 3.318 & 1 & 6 & 1 & 85 & 9 \\
Lubuk & 2.226 & 128 & 8 & 0 & 129 & 9 \\
Jumlah & 27.783 & 314 & 890 & 3 & 3.206 & 233 \\
\hline
\end{tabular}

Sumber: Profil Kecamatan Kundur 2018

Berdasarkan Tabel 1.1 diatas sebagian besar penduduk di kecamatan kundur menganut agama Islam yaitu sebanyak 27.783 jiwa, kemudian penganut agama Budha 3.206 jiwa, agama Protestan 890 jiwa, agama Katolik 314 jiwa, agama Hindu 3 jiwa, dan agama konghucu 233 jiwa. Dalam penelitian ini saya ingin melihat bagaimana kerukunan umat beragama walaupun hidup di daerah heterogen.

Tanjung Batu merupakan daerah yang memiliki keberagaman dalam menjalankan kehidupan beragama, agama yang di anut oleh masyarakat Tanjung Batu sebagai Berikut. Islam, Budha, Kristen, Protestan, Hindu, dan Konghuchu. Dengan keberagaman tersebut penulis tidak menemukan permasalahan yang muncul atar pemeluk agama dengan contoh kasus konflik singkel yang terekspos pada linimasa tidak bisa dihindari bahwa adanya gesekangesekan kecil di masyarakat Tanjung Batu.

faktor penyebab tidak pernah terjadinya konflik agama di Tanjung Batu Kota Kec Kundur Kab Karimun yang menciptakan hubungan yang harmonis antar masyarakat di Tanjung Batu terlihat harmonis sehingga terwujudnya kerukunan antar pemeluk agama.

Berdasarkan masalah diatas peneliti ingin melakukan penelitian tentang "Manajemen antar umat beragama Studi Kasus: Umat Agama Islam dan Umat Agama Budha di Tanjung Batu Kec. Kundur Kab. Karimun”. 


\section{METODE PENELITIAN}

Penelitian ini memakai metode penelitian kualitatif deskriptif kualitatif deskriptif (Maleong, 2013). Peneliti menggunakan tipe deskriptif ini karena dapat menggambarkan dan menjelaskan faktor penyabab tidak pernah terjadinya konflik di Tanjung

Batu Kota Kecamatan Kundur Kabupaten Karimun.

Penelitian ini memakai purpive sampling adalah sebelum melakukan penelitian peneliti menetapkan kriteria tertentu yang mesti dipenuhi oleh orang yang dijadikan sumber informasi (Afrizal, 2014). Adapun kriteria informan yang menjadi fokus penelitian adalah: Kasi Sosial kontor kelurahan Tanjung Batu Kota, Pengurus dalam pengelolaan tempat beribadah umat Islam dan Budha di Tanjung Batu Kota Kec. Kundur, Kantor Polisi Tanjung Batu Kundur, Masyarakat Tanjung Batu kota yang berbeda agama.

Data primer dalam penelitian ini adalah hasil wawancara dari informan yang sesuai dengan kriteria yang ditetapkan oleh penelitian yang mana informan penelitian ada 9 orang. Sedangkan Data sekunder adalah data yang diperoleh dari sumber yang sudah ada / pihak lain, seperti dokumen resmi, surat-surat, dari berbagai lembaga pemerintah atau swasta (Lufri, 2007). Data sekunder dalam penelitian ini diperoleh dari Kantor Lurah dan Kantor Camat Kundur seperti SK pembentukan Forum Kerukunan Umat Beragama (FKUB), SKD dan Surat Pernyataan dari kepolisian.

Analisis Data penelitian ini menggunakan Model Interaktif (Interactif Model Of Analisis) Milles dan Huberman bahwa telaah bahan terdiri dari 4 aturan kegiatan yang terjadi diwaktu yang sama yakni, pengumpulan data, penyajian data, penyusutan data, dan menarik rangkuman/verifikasi.

\section{HASIL DAN PEMBAHASAN}

Gambara Umum Masyarakat Tanjung Batu Kota

Tanjung batu Kota merupakan salah satu wilayah di Kecamatan Kundur Kabupaten Karimun yang memiliki potensi sumber daya alam yang bagus dan sejarah masa lampau yang cukup menarik. Hingga kini Tanjungbatu Kota menjadi Ibu kota Kecamatan Kundur. 
Kecamatan Kundur juga merupakan salah satu daerah yang memiliki masyarakat dan budaya yang beragam, salah satunya kelurahan di Kecamatan Kundur yang memiliki keragaman agama dan etnis dalam masyarakatnya adalah kelurahan Tanjung Batu Kota. Kelurahan Tanjung Batu Kota adalah daerah yang memiliki interaksi dan hubungan yang baik antar umat beragama. Dengan adanya interaksi dan hubungan yang baik antar umat beragama diharapkan terciptanya keharmonisan dalam masyarakat kelurahan Tanjung Batu Kota.

Program Kebersihan Lingkungan di Tanjung Batu Kecamatan Kundur

\section{Sabtu Bersih}

Kelurahan ini mempunyai program sabtu bersih, yaitu gotong royong bersama untuk kebersihan lingkungn kita ini, masayarakat di daerah Tanjung Batu ini bahwa mereka bisa hidup saling tolong menolong walaupun mereka ada perbedaan agama, hidup mereka rukun-rukun saja dan mereka juga sering melakukan gotong royong bersama untuk membersihkan daerah mereka.
Program ini bisa menimbulkan rasa saling peduli antara lain rasa terhadap lingkungan mereka dan secara tidak langsung juga terjadi suatu komunikasi dan sekaligus interaksi antar umat agama Islam Dan Budha yang dapat menunbuhkan sautu kerukunan antar kedua masyarakat Tanjung Batu Kota.

Saling Mendukung dalam Kegiatan Keagama

1. Musabaqoh Tilawatil Quran (MTQ)

kegiatan MTQ di Tanjung Batu Kecamatan Kundur ini tidak hanya melibatkan masyarakat Muslim saja tetapi juga terdapat peran umat agama lain contohnya umat agama Budha mereka juga ikut serta melancarkan kegiatan ini dengan cara memberi sedikit lahan tempat mereka berdagang untuk melancaran kegiatan MTQ di Tanjung Batu Kota Kecamatan Kundur.

Masyarakat di Tanjung Batu orangnya lebih saling mengahargai dan sangat menjaga kerukunan sebab semuanya mau untuk bekerja sama untuk daerah mereka. Misalnya dalam perayaan MTQ (musabaqah tilawatil qur'an) agama budha mau 
untuk saling kerja sama dalam kelancaran acara MTQ tersebut dengan memberi sedikit lokasi yang berada di emperan toko untuk di dirikannya stand bazar di acara MTQ tersebut.

\section{Cap Go Meh}

Perayaan ini akan dimeriahkan dengan permainan Barongsai Oleh anak muda etnis tionghoa atau disebut juga masyarakat budha acara inti pada kegiatan ini terdiri dari atraksi hiburan dan tradisi hiburan yang pada dasarnya dapat dinikmati oleh etnis tiongha serta masyarakat di tempat kegiatan.

Perayaan

Cap

Go

Meh mengandung makna spiritual yang diyakini besar manfaatnya bagi seluruh masyarakat. Masayarakat disini, baik masayarakat muslim maupun masyarakat non muslim bekerja sama saling tolong menolong, saling menghargai dan saling menghormati agama lain. Seperti halnya ketika masayarakat budha ingin mengadakan kegitaan keagamaan mereka masayarakat budha akan terlebih dahulu memberikan informasi kepada agama lain. Misalnya pada saat masayarakat budha mengadakan kegiataan keagamaan di waktu malam masyarakat budha selalui memulai acara kegiatan setelah selesai ibadah sholat isya agama islam, agar masayarakat budha tidak mengganggu ibadah mereka.

Tanjung Batu Kota ini saling mendukung dalam hal perayaan kegiatan Keagamaan antar umat baragama bahwa msayarakat di Tanjung Batu hidup saling bertoleransi.

Faktor yang Melatar belakangi Terjadinya Intergrasi Sosial di Tanjung Batu Kota Kecamatan Kundur

\section{Teloransi di Bidang Ekonomi}

Masyarakat agama budha di Tanjung Batu Kota pada umumnya memiliki mata pencariannya sebagai pengusaha, masayarakat agama budha membuka peluang kerja bagi umat agama lain yang mencari nafkah untuk memenuhi kebutuhan hidup mereka. Di Tanjung Batu Kota masyarakatnya tidak pernah memandang latar belakang agama maupun kebudayaan yang berbeda.

Kerja sama yang tercipta di Tanjung Batu Kota sudah terlihat jelas dari bentuk kerja sama yang 
terjalin seperti dibidang ekonomi. Kerja sama yang terjalin dalam masyarakat atau aktivitas kehidupan bermasyarakat di bidang ekonomi adalah dalam kegiatan usaha ekonomi yang digunakan prinsip kerja sama, saling membantu dalam suasana demokrasi ekonomi untuk mencapai kesejahteraan bersama secara adil. Salah satu nyata asas kekeluargaan adalah adanya kerja sama atau gotong royong dalam membangun perekonomian bangsa.

Masyarakat agama budha di Tanjung Batu Kota pada umumnya memiliki mata pencariannya sebagai pengusaha, masayarakat agama budha membuka peluang kerja bagi umat agama lain yang mencari nafkah untuk memenuhi kebutuhan hidup mereka. Di Tanjung Batu Kota masyarakatnya tidak pernah memandang latar belakang agama maupun kebudayaan yang berbeda. Masayarkat di Tanjung Batu Kota menerapkan hubungan simbiosis mutualisme sehingga terjalin kerja sama yang baik dalam masayarakat.

Masyarakat di Tanjung Batu saling membutuhkan satu sama lain dengan adanya interaksi yang baik maka akan terbentuknya kerukunan antar umat beragama di Tanjung Batu Kota ini. Persekutuan antara agama adalah segmen daei interaksi, sosial antar penduduk yang tidak larang pada petunjuk beragama. Interaksi dan persekutuan di bidang sector ekonomi tidak dilarang, akan tetapi dianjurkan yang mana tetap berada pada lingkup kebaikan. Dengan adanya pernyataan diatas sebagai pemeluk agama yang menganut agama berbeda dapat membuat sebuah kerja sama yang baik untuk seluruh elemen masyarakat.

2. Saling Menghormati dan Menghargai Agama Lain

Masyarakat Kelurahan Tanjung Batu terdapat masyarakat muslim dan non muslim memiliki agama yang beragama yang berbeda, dimana masing-masing mereka menjunjung tinggi nilai-nilai yang berbeda. Di Tanjung Batu keberagaman agama tidak menjadi perdebatan dan persoalan bagi masyarakat, justru dengan adanya perbedaan di antara masyarkat mereka bisa belajar bagaimana untuk 
saling menghargai dan menghormati suatu perbedaan.

Hubungan umat agama disini masih terlihat harmonis masih ada saling menghargai antar umat beragama, kami disini tidak pernah membeda-bedakan agama lain sifat menjelek-jelekan agama lain itu tidak ada justru kami membangun antara satu sama lain rasa saling menghormati dan menghargai yang kami tamankan di masayarakat. masyarakat Tanjung batu ini hidupnya saling rukun dan saling menghormati, misalnya kalau agama islam sedang sholat kami tidak akan mengganggu ibadah mereka begitu pula sebaliknya mereka juga tidak akan mengganggu ibadah kami.

\section{Interaksi Antar Umat Beragama}

Interaksi adalah proses mempersatukan masyarakat yang cenderung membuatnya menjadi satu kota yang harmonis yang didasarkan pada tantanan oleh anggota dianggap sama harmonisnya, dimana masayarakat muslim maupun masyrakat nonmuslim bekerja sama saling tolong menolong, saling menghargai dan saling menghormati agama lain.
Ketika interaksi dan komunikasi terjalin dengan baik antar semua kelompok maka dapat diciptakan lingkungn yang harmonis serta terjadinya rukun antar sesama dan juga dapat menjauhkan mereka dari perselisihan serta menjatuhkan antar umat beragama. Seperti pada saat umat muslim sedang melaksana puasa di saat buala Romadhan umat agama lain saling menghormati dan mereka juga menutupi kedainya agar tidak merusak ibadah puasa umat muslim. Begitu juga sebaliknya masayarakat budha ingin mengadakan kegitaan keagamaan mereka masayarakat budha akan terlebih dahulu memberikan informasi kepada agama lain. Misalnya pada saat masayarakat budha mengadakan kegiataan keagamaan di waktu malam masyarakat budha selalui memulai acara kegiatan setelah salesai ibadah sholat isya agama islam, agar masayarakat budha tidak mengganggu ibadah mereka.

Masyarakat Tanjung Batu Kota ini belum pernah lagi terjadinya konflik antar umat karena masyarakat di Tanjung Batu hidup 
dengan saling menghargai satu sama lain dan saling menghormati, memiliki teloransi yang tinggi dan saling berinteraksi yang baik sehingga membuat mereka bisa hidup dengan rukun, dengan kerja sama yang baik itu membuat Tanjung Batu Kota tidak pernah terjadinya konflik.

4. Adanya Forum Kerukunan Umat Beragama di Tanjung Batu Kecamatan Kundur

Forum Kerukunan Umat Berkeyakian atau agama (FKUB) ialah forum konferensi tokoh agama. Forum ini berperan sebagai forum hubungan antar umat beragama yang memiliki tujuan menjauhi kekerasan atas agama tertentu. Forum Kerukunan Umat Baragama (FKUB) di Tanjung Batu adalah sebuah organisasi yang keberadaanya berdasarkan SK Camat Kundur Tanjung Batu No. 02/thn/2008, tanggal tanggal 19 Januari 2006 dan Peraturan Bersama Menteri Agama dan Menteri Dalam Negeri No. 9 Dan No. 8 Tahun 2006.

Faktor yang membuat Tanjung Batu ni terlihat aman dan damai tidak pernah terjadinya konflik juga karna di Tanjung Batu ini ada di dirikannya FKUB "Forum Kerukunan Umat Beragama" dan BKAG "Badan Kerja Sama Antar Agama" di dalam forum tersebut beranggotakan dari masingmasing agama yang ada di Tanjung Batu. Jadi kalau ada masalah mengenai keagamaan mereka akan cepat untuk menyelesaikan permasalahan tersebut biar tak berlarut-larut dan menjadi besar masalahnya.

Tugas-tugas dari FKUB di Tanjung Batu Kota adalah sebagai berikut, yaitu: Melakukan dialog dengan pemuka agama dan tokoh masyarakat, Menampung aspirasi ormas keagamaan dan aspirasi masyarakat, Menyalurkan aspirasi ormas keagamaan dari masyarakat dalam bentuk rekomendasi sebagai bahan kebijakan Camat, Melakukan sosialisasi peraturan perundangundangan dan kebijakan di bidang keagamaan yang berkaitan dengan kerukunan umat beragama dan pemberdayaan masyarakat dan Memberikan rekomendasi tertulis atas permohonan pendirian rumah ibadah. 
Salah satu cara untuk mereka sendiri dengan begitu akan mempertahankan hubungan kerukunan dan keharmonisan di daerah Tanjung Batu Kecamatan Kundur masyarakat membentuk suatu organisasi yang bernama FKUB "Forum Kerukuna Umat Beragama" yang beranggotakan dari masing-masing pemeluk agama yang ada di Tanjung batu Kecamatan Kundur.

Jadi peneliti ini menganalisis menggunakan Teori Konflik menurut Lewis A Coser konflik ialah merupakan unsur interaksi sangat penting, dan sama sekali tidak boleh dikatakan bahwa konflik selalu tidak baik atau memecah bela ataupun merusak. (Dwi \& K, 2008) Konflik juga bisa saja menyumbang banyak kepada kelesatarian/kekompakan kelompok dan mempererat hubungan antar anggotanya seperti yang dialami masyarakat di Tanjung Batu di Kecamatan Kundur ini mereka menghadapi musuh bersama dapat mengintegrasikan, sehingga terciptanya solidaritas dan keterlibatan, dan membuat orang lupa akan perselisihan internal terciptanya kerukunan.

Ketika konflik berlangung, Coser menyampaikan cara penyelesaian dengan konsep katup penyelamat. Karena melihat katup penyelamat ini menjadi jalan keluar penyelesaian yang menenteramkan permusuhan yang tanpa itu hubungan antara pihak yang berselisih akan semakin tajam.

Dalam penelitian ini kutup penyelamt (safety valve) masyarakat Tanjung Batu Kecamatan Kundur ini adalah Institusi yang menjadi tempat masyarakat menyampaikan keluhan, menyalurkan persoalan, atau masalah-masalah yang dialami oleh masyarakat Tanjung Batu Kota Kecamatan Kundur. Dan yang menjadi Safety valve kehidupan sosial antar umat beragama di Tanjung Batu Kecamatan Kundur ini adalah organisasi yang bernama FKUB yang membantu menyelesaikan permasalahn keagama yang terjadi di Tanjung Batu Kota. FKUB ini ditetapkan oleh Institusi kecamatan kundur atas keputusan Camat Kundur untuk mengatur 
kehidupan bermasyarakat, agar terhindar dari konflik.

Jadi safety valve kehidupan sosial antar umat agama Islam dan Budha di Tanjung Batu Kecamatan Kundur yaitu sebuah institusi yang anggotanya merupakan pemimpinpemimpin pemerintah, FKUB yang beranggotakan diri masing-masing agama yang ada di Tanjung Batu Kota Kecamatan Kundur yang ditentukan oleh persetujuan masyarakat yang tinggal di Tanjung Batu Kota.

\section{KESIMPULAN}

Kecamatann Kundur merupakan salah satu daerah yang memiliki masyarakat dan budaya yang beragam, yang dimana mereka memiliki beraneka ragam etnis serta agamanya. Interaksi dan hubungan sosial yang terjadi antara Umat agama Islam dan agama Budha sudah terjalin dengan baik. Buktinya mereka menjalin kerja sama yang baik dalam bentuk saling menghargai dan menghormati satu sama lain dengan adanya bukti kerja sama di bidang ekonomi, bidang sosial yang membuat mereka menjalin hidup rukun sampai saat ini.

Hubungan interaksi di Tanjung Batu juga dapat di lihat bagai mana mereka saling menghargai satu sama lain dengan cara ikut serta merayakan hari besar ke agamaan contohnya dalam perayaan Imlek dan Idul Fitri meraka saling menghormati dan mengarhai dengan berkunjung dan bersilaturahmi satu sama lain. Oleh sebab itu perlu dikembangkan lagi sikap saling memahami, mengormati, menghargai, bekerja sama dan saling berteloransi di lingkungan tempt tinggal untuk menciptakan kedamaian.

\section{DAFTAR PUSTAKA}

Afrizal. 2014. Metode Penelitian Kualitatif. Jakarta: PT Raja Grafindo Persada.

Dwi Susilo, Rahmad K. 2008. 20 Tokoh Sosilogi Modren. Yogyakarta. Arruz Media.

Khamad, D. 2006. Sosiologi Agama. Bandung: Remaja Rosdakarya.

Lubis, M. Abud. 2017. "Budaya Dan Solidaritas Sosial Dalam Kerukunan Umat Beragama Di Tanah Karo." Jurnal Ilmiah Sosiologi Agama Dan Perubahan Sosial 11(2):23940. 
Lufri. 2007. Kiat Memahami Metodologi Melakukan Penelitian. padang: UNP PRESS.

Maleong. 2014. Metodologi Penelitian Kualitatif. Jakarta: Remaja Rosdakarya.
Wiranta, Irwan Hadi and Marzuki. 2018. "Kerukunan Antarumat Beragama Sebagai Dasar City Branding Harmoni Kediri The Service City." Jurnal Ilmiah Pendidikan Pancasila Dan Kewarganegaraan 3(1):65. 